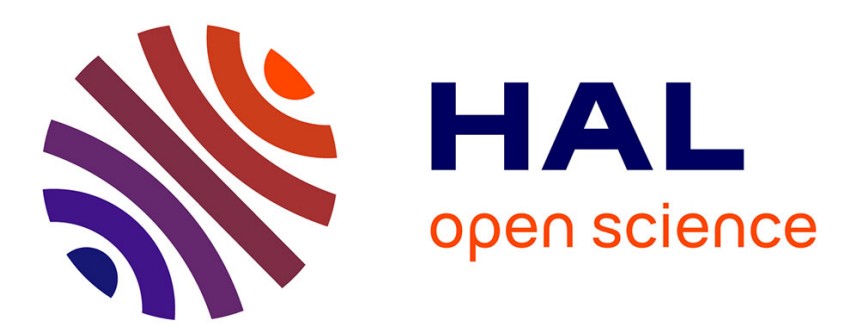

\title{
Efficiency of pyoverdines in iron removal from flocking asbestos waste: An innovative bacterial bioremediation strategy
}

Sébastien R David, Dris Ihiawakrim, Robert Regis, Valérie Geoffroy

\section{- To cite this version:}

Sébastien R David, Dris Ihiawakrim, Robert Regis, Valérie Geoffroy. Efficiency of pyoverdines in iron removal from flocking asbestos waste: An innovative bacterial bioremediation strategy. Journal of Hazardous Materials, 2020, 394, pp.122532. 10.1016/j.jhazmat.2020.122532 . hal-03079408

\section{HAL Id: hal-03079408 \\ https://hal.science/hal-03079408}

Submitted on 17 Dec 2020

HAL is a multi-disciplinary open access archive for the deposit and dissemination of scientific research documents, whether they are published or not. The documents may come from teaching and research institutions in France or abroad, or from public or private research centers.
L'archive ouverte pluridisciplinaire HAL, est destinée au dépôt et à la diffusion de documents scientifiques de niveau recherche, publiés ou non, émanant des établissements d'enseignement et de recherche français ou étrangers, des laboratoires publics ou privés. 


\section{Efficiency of pyoverdines in iron removal from flocking asbestos waste: an innovative bacterial bioremediation strategy}

${ }^{\text {a } U n i v e r s i t e ́ ~ d e ~ S t r a s b o u r g, ~ C N R S-U M R 7242, ~ B S C, ~ E S B S, ~} 300$ Bld Sébastien Brant, 67413 Illkirch, Strasbourg, France

${ }^{\text {b }}$ Agence de l'Environnement et de la Maîtrise de l'Energie, 20 avenue du Grésillé, BP 90406, 49004 Angers Cedex 01, France

c Université de Strasbourg, CNRS-UMR7504, IPCM, 23 rue du Loess, BP 43, 67034 Strasbourg, France

d SOMEZ, Parc Marcel Dassault, 470 Rue Alberto Santos Dumont, 34430 Saint Jean de Vedas, France

* Corresponding authors : V. A. Geoffroy, UMR 7242, Université de Strasbourg-CNRS, ESBS, Biotechnologie et Signalisation Cellulaire, Bd Brant, CS 10413, F-67412 Illkirch Cedex France. Email : valerie.geoffroy@unistra.fr Tel. (+33) 368854751 Fax $(+33) 368854829$

\section{Abstract}

The use of asbestos-containing products has been banned in many countries since the beginning of the 80 's due to its carcinogenic properties. However, asbestos is widely present in private and public buildings, resulting in the need to process a vast amount of asbestos-containing waste. Among the current technologies for the destruction of asbestos fibers, biodegradation by fungi, lichens, and, more recently, bacteria has been described. We previously reported the involvement of the bacterial siderophore pyoverdine in the release of iron from the two asbestos groups, serpentines and amphiboles. Among the large diversity encountered in the pyoverdine family, we examined whether these siderophores can alter flocking asbestos waste as well. All the tested pyoverdines were efficient in chrysotile-gypsum and amosite-gypsum weathering, although some exhibited higher iron dissolution. Iron was solubilized by pyoverdines from Pseudomonas aeruginosa and mandelii in a time-dependent manner from chrysotile-gypsum within 24 hours. Renewal of pyoverdine-containing supernatant every 24 or 96 hours allowed iron removal from chrysotile-gypsum at each cycle, until a limit was reached after 42 days of total incubation. Moreover, the dissolution was concentration-dependent, as demonstrated for the pyoverdine of 
P. mandelii. Pyoverdine-asbestos weathering could therefore become an innovative method to reduce anthropogenic waste.

\section{Keywords}

Pyoverdine- Pseudomonas-Asbestos-Iron-Alteration

\section{Introduction}

Asbestos has been extensively used because of its excellent properties, such as thermal conductivity, high mechanical strength, resistance to chemical attacks, and low cost. Asbestos is composed a group of fibrous silicate minerals that belong to the serpentine and amphibole families. Amphiboles can contain up to $36 \%$ iron by weight, whereas the serpentine form of asbestos contains only 2 to $3 \%$ iron by weight (Chao and Aust, 1994). Iron can be present as part of the mineral structure in the amphibole or as an exchangeable element in the chrysotile (Douguet et al., 1997; Virta, 2002). The iron encountered in asbestos is able to catalyze many reactions, such as lipid peroxidation, oxygen consumption, ROS formation, and DNA damage, precursors for tumor development (Toyokuni, 2009; Valko et al., 2015). The various types of toxic effects in humans include fibrogenesis and stomach, ovarian, and lung cancer (Scherpereel, 2016). Due to the associated health problems, asbestos was banned after more than 30 years of intense use. As a consequence, we are confronted with the generation of a vast amount of asbestos-containing waste (ACW).

Today, most waste is packed and deposited in controlled landfills, an inexpensive technique that does not remove the toxicity or potential health risk of waste related to fiber inhalation (Spasiano and Pirozzi, 2017). ACW treated by stabilization aims to reduce the fibers released, without modifying the crystalline structure, and ends up in landfills. The second type of treatment, called inertization, consisting of thermal treatment (vitrification or microwave), or hydrothermal, chemical, or mechanochemical treatment, involves the total transformation of the fibers, providing an inert and harmless material, considered to be a resource. However, such thermal treatment is expensive due to energy consumption and may release emissions into the atmosphere. Chemical treatment requires chemical products and their disposal, but has allowed confirmation of the potential Mg released (Paolini et al., 2019). At the laboratory scale, bioremediation experiments have been carried out on raw asbestos using various organisms 
61 (fungi, lichens, or bacteria) or metabolites (organic acids or siderophores), whereas few studies have focused on ACW. A few studies have focused on asbestos-cement waste, whereas none have investigated biological treatment of flocking asbestos waste (FAW), of which the matrix composition differs, containing gypsum to allow flocking to walls instead of cement. For example, lichens are able to cover asbestos-cement roofs and modify the surface reactivity, leading to bioavailable iron and magnesium liberation (Favero-Longo et al., 2009). Moreover, modification of the fibers has been described, by which they became amorphous, due to oxalic acid production (Favero-Longo et al., 2005) and nitrous and nitric acid produced by nitrifying bacteria, such as Nitrosomonas and Nitrobacter, inducing corrosion of a cement-roof, thus increasing porosity and reducing the strength of the material (Wasserbauer et al., 1988). Moreover, Wang et al. $(2010,2011)$ also highlighted the porous structure of cement pipes after microorganism colonization. They showed that acid-producing bacteria together with slimeforming and heterotrophic bacteria contribute to corrosion of the inside surface of asbestoscement pipes of water distribution systems. Innovative bio-chemical processes have been recently proposed, in which the cement phase is dissolved by lactic acid produced by Lactobacilli or by dark fermentation, before hydrothermal end treatment (Balducci et al., 2012; Spasiano et al., 2017). Siderophore production is a common mechanism shown in fungal and bacterial weathering of native asbestos, leading to iron dissolution from fibers (Daghino et al., 2010; Rajkumar et al., 2009). Siderophores are a well-known strategy that many living organisms use to access iron, an essential element for growth. In mineral-bacterial weathering, various siderophores have been implicated in iron dissolution, resulting in leaching of the material, and pyoverdine (PVD) has been described to interact with iron-bearing silicates, such as smectite (Ferret et al., 2014) and municipal waste-bottom ashe (Aouad et al., 2008). However, this mechanism has not yet been investigated on ACW. We thus investigated the impact of the bacterial siderophore PVD, produced by fluorescent Pseudomonas, on FAW. In building construction, two types of FAW have been described, varying in texture, thickness, and density. The first type used in this study contained 50 to $90 \%$ chrysotile fibers $\left(\left(\mathrm{Mg}_{3} \mathrm{Si}_{2} \mathrm{O}_{5}(\mathrm{OH})_{4}\right)\right.$ and 10 to $50 \%$ gypsum $\left(\mathrm{CaSO}_{4}, 2 \mathrm{H}_{2} \mathrm{O}\right)$, whereas the second contained 5 to $30 \%$ chrysotile fibers and 95 to $70 \%$ gypsum. Amphibole fibers, such as amosite $\left((\mathrm{Fe}, \mathrm{Mg})_{7} \mathrm{Si}_{8} \mathrm{O}_{22}(\mathrm{OH})_{2}\right)$, have also sometimes been combined with FAW. The ability of pyoverdine to extract iron from fiber has 
91 already shown on chrysotile and amphibole raw asbestos. However, two main difficulties such as the iron pollution present in the matrix and the fiber accessibility may interfere with the iron extraction by pyoverdine.

Among the 100 PVDs so far described by siderotyping fluorescent Pseudomonas, their affinity for iron is not yet known. We therefore tested several representatives from the PVD laboratory collection to determine their ability to scavenge iron from ACW and selected the most efficient. Iron removal was tested as a function of PVD concentration and the optimum time for FAW alteration determined. Long-term alteration experiments by the best identified PVDs determined the iron extraction limit.

\section{Experimental}

\subsection{Asbestos wastes preparation}

Two types of flocking asbestos wastes were used, chrysotile-gypsum and amosite-gypsum. These wastes come from the asbestos removal site of Jussieu University of Paris and kindly provided by the Mediterranean Company of Zeolites (SOMEZ). To obtain amosite-gypsum, FAW samples were incubated in an acidic bath with sulfuric acid $(8 \mathrm{~mol} / \mathrm{L})$, until total dissolution of the chrysotile brucite layer. All asbestos samples $(0.2 \mathrm{~g})$ were sterilized by autoclave $\left(121^{\circ} \mathrm{C}\right.$ for $\left.20 \mathrm{~min}\right)$ and incubated at $70^{\circ} \mathrm{C}$ for 14 days before experiments. Before each experiment, asbestos samples were washed with $20 \mathrm{~mL}$ of sterile succinate medium to remove free $\mathrm{Fe}$ and $\mathrm{Mg}$.

\subsection{Bacterial strains}

Bacteria used in this study were listed in table 1 . Strains were stored in LB-20 \% glycerol stock at $-80^{\circ} \mathrm{C}$. Pseudomonas cells were grown routinely overnight at $30^{\circ} \mathrm{C}$ in Luria Bertani medium (LB) under shaking condition (220 rpm).

\subsection{Production of pyoverdines}

$1 \mathrm{~mL}$ of overnight LB culture of Pseudomonas strains was centrifuged ( $3 \mathrm{~min}$ at $9871 \mathrm{~g}$ ). For iron starved cells, the iron-deficient succinate medium (composition in g.L ${ }^{-1}: \mathrm{K}_{2} \mathrm{HPO}_{4}, 6.0$; 
$\mathrm{KH}_{2} \mathrm{PO}_{4}, 3.0 ;\left(\mathrm{NH}_{4}\right)_{2} \mathrm{SO}_{4}, 1.0 ; \mathrm{MgSO}_{4} .7 \mathrm{H}_{2} \mathrm{O}, 0.2$; sodium succinate, $4.0 ; \mathrm{pH}$ adjusted to 7.0 by addition of $\mathrm{NaOH}$ ), sterilized by $0.2 \mu \mathrm{m}$ filtration, was used (Meyer and Abdallah, 1978). The pellet, washed twice with $1 \mathrm{ml}$ of sterile succinate medium, was suspended in $1 \mathrm{ml}$ of sterile succinate medium and inoculated in $15 \mathrm{~mL}$ of sterile succinate medium, incubated at $30^{\circ} \mathrm{C}$ under shaking condition $(220 \mathrm{rpm})$. After $24 \mathrm{~h}$ of growth, $7.5 \mathrm{~mL}$ of this culture was transferred in an Erlenmeyer flask containing $1 \mathrm{~L}$ of sterile succinate medium. After $24 \mathrm{~h}$ of incubation at $30^{\circ} \mathrm{C}$ under shaking condition $(220 \mathrm{rpm})$, the culture was centrifuged (2664 g for $40 \mathrm{~min}$ ). The supernatant was filtered twice with glass microfibre filters (Whatman, GF/C) and once on nitrocellulose filter $\left(0.45 \mu \mathrm{m}\right.$ porosity). To determine pyoverdine concentration, $\mathrm{OD}_{400}$ was measured with a Specord 205 spectrophotometer (Analytik Jena). When needed, the PVD concentration was adjusted with purified PVD according to the method described so far. Siderophore containing supernatant was loaded, after acidification ( $\mathrm{pH}$ 6.0), on XAD-4 column, washed with two volume of purified water and eluted with one volume of $50 \%$ ethanol. The eluate was concentrated under vacuum on a rotary evaporator and lyophilized.

\subsection{Asbestos dissolution by pyoverdines}

To evaluate the effect of various PVDs on the dissolution of iron from chrysotile-gypsum and amosite-gypsum, $20 \mathrm{~mL}$ of PVD-containing supernatants adjusted to $100 \mu \mathrm{M}$ were incubated with materials in $50 \mathrm{~mL}$ Falcon tubes. After $24 \mathrm{~h}$ of incubation at $30^{\circ} \mathrm{C}$ under shaking condition $(220 \mathrm{rpm})$, the assays were centrifuged $30 \mathrm{~min}$ at $9871 \mathrm{~g}$ to recover supernatants. Assays were done in 3 to 5 replicates.

Kinetics of iron dissolution from chrysotile-gypsum in $20 \mathrm{~mL}$ of PVD-containing supernatant of $P$. aeruginosa and $P$. mandelii respectively adjusted to $100 \mu \mathrm{M}$ were followed on 24 hours with regular sampling of the solution at 1, 2, 4, 6, 8 and $24 \mathrm{~h}$. Assays were done in 5 replicates.

Long-term alteration of chrysotile-gypsum by PVD-containing supernatant of $P$. aeruginosa and P. mandelii was performed by renewal cycles at $30^{\circ} \mathrm{C}$ under shaking condition (220 rpm). Nine cycles of 24 hours and seven cycles of $96 \mathrm{~h}$ were realized in the presence of 100 $\mu \mathrm{M}$ of PVD-containing supernatant, followed by a 24 and a $96 \mathrm{~h}$ cycles with $200 \mu \mathrm{M}$ of PVDcontaining supernatant. Assays were done in 5 replicates. 

magnesium dissolution from chrysotile-gypsum, material was incubated during $48 \mathrm{~h}$ at $30^{\circ} \mathrm{C}$ under shaking condition (220 rpm) with $20 \mathrm{~mL}$ of supernatant adjusted to 25, 50, 100, 150 and $200 \mu \mathrm{M}$. Assays were done in 5 replicates.

Materials were eliminated from supernatants by filtration $(0.22 \mu \mathrm{m}$ porosity). Iron and magnesium content were measured depending on the experiment.

156

\subsection{Determination of $\mathrm{Fe}$ and Mg contents}

In order to determine iron content, we used the bathophenanthroline method, which is a sensitive colorimetric method for determining ferrous iron content. To determine the total iron, ferric iron was converted to ferrous iron by thioglycolic acid. Each sample was analyzed in triplicate. $20 \mu \mathrm{L}$ of sample were dispensed into each well of a 96-well plate (Greiner, PS flatbottomed microplate). $40 \mu \mathrm{L}$ of saturated sodium acetate (5.5 M) (Sigma-Aldrich), $80 \mu \mathrm{L}$ of cold distilled water, $10 \mu \mathrm{L}$ of a thioglycolic acid solution diluted 10 times in water (Sigma-Aldrich) and $10 \mu \mathrm{L}$ of bathophenanthroline $\left(5 \mathrm{mg} \cdot \mathrm{mL}^{-1}\right)$ (Sigma-Aldrich) were additionned per well. After shaking, microplates were stored overnight at $4^{\circ} \mathrm{C}$. Absorbance was measured at $535 \mathrm{~nm}$ in a Tecan microplate reader (Infinite M200, Tecan) and iron concentration (mg.L ${ }^{-1}$ ) was determined by reference to a standard curve.

For the magnesium content, calmagite method was used. Magnesium formed a coloured complex with calmagite. EGTA (Ethylene Glycol Tetraacetic Acid) was used to eliminate any calcium interference. Each sample was analyzed in triplicate. To prepare the reactive solution, one volume of reagent 1 (1 mol.L $\mathrm{L}^{-1}$ of 2-Methyl-2-Amino-1-Propanol and $215 \mu \mathrm{mol.L}{ }^{-1}$ of EGTA) with one volume of reagent $2\left(300 \mu \mathrm{mol}^{-\mathrm{L}^{-1}}\right.$ of calmagite) were mixed. $3 \mu \mathrm{L}$ of sample were dispensed into each well of a 96-well plate (Greiner, PS flat-bottomed microplate) and 300 $\mu \mathrm{L}$ of reactive solution mixed were added. After shaking and 30 seconds of incubation, absorbance was measured at $500 \mathrm{~nm}$ in a Tecan microplate reader (Infinite M200, Tecan) and magnesium concentration (mg. $\mathrm{L}^{-1}$ ) was determined by reference to a standard curve.

\subsection{STEM-EDX of asbestos fibers}


TEM (Transmission Electron Microscopy) images were recorded with a JEOL 2100 microscope, with a $200 \mathrm{kV}$ potential applied on a LaB6 filament as an electron source.

181 Resolution of the TEM is $0.21 \mathrm{~nm}$. TEM mapping was performed in STEM (Scanning transmission electron microscopy) mode (resolution $2 \mathrm{~nm}$ ) and using an SSD-EDX (Silicon Drift Detector-Energy Dispersive X-ray) spectrometer to determine the chemical composition.

\subsection{Statistical analysis}

Results presented in all figures correspond to mean values of three to five replicates. Significant statistical differences among values were determined using Kruskal-Wallis test (RStudio v1.0.153) followed by a Conover post-hoc analysis. Values with the same letter are not significantly different at $p=0.05$.

190

\section{Results and discussion}

\subsection{Efficiency of pyoverdines on iron removal from flocking asbestos wastes}

PVDs, yellow-green fluorescent pigments, are composed of three moieties: (i) a peptide chain varying in the nature, number, and order of amino acids, (ii) a dihydroxyquinoline chromophore, conferring the yellow-green color of the molecule, and (iii) an acyl chain radical made of dicarboxylic acid residue which can be either succinate, malate, or their amide forms, or alpha-ketogluratate or glutamate, depending on the producing strain and growth conditions. Based on these structural differences, PVDs have been purified from various Pseudomonas strains to obtain a large family composed of more than 100 different structures, depending on their peptide chain and radical $\mathrm{R}$ (Meyer et al., 1998). PVD binds to $\mathrm{Fe}^{3+}$ in a $1: 1$ stoichiometry with a stability constant for Fe(III) of approximately $10^{32} \mathrm{M}^{-1}$ for PVD produced by $P$. aeruginosa PAO1 (Albrecht-Gary et al., 1994). From this bank, we selected nine PVDs produced by various Pseudomonas species based on their different isoelectrofocusing profile related to the length, nature, and presence of cycle rings in the peptide chain (Table 1). These selected PVDs were tested to investigate potential differences in their ability to chelate iron. We previously showed that purified PVDs can extract iron from the three native asbestos types, chrysotile, amosite, and crocidolite, and with the same efficiency as PVD-containing supernatant (David et 
al., 2019). Therefore, we used PVD-containing supernatants to determine the effect of these siderophores on FAW, chrysotile-gypsum, and amosite-gypsum (Fig. 1). The nine selected PVDs (at a concentration of $100 \mu \mathrm{M}$ ) were incubated with each FAW for $24 \mathrm{~h}$. The control medium (sterile succinate medium) had no visible effect on iron dissolution from waste, whereas all tested PVDs exhibited significant iron extraction from both types of waste, ranging from 0.24 mg. $\mathrm{L}^{-1}$ to $1.22 \mathrm{mg} . \mathrm{L}^{-1}$ iron dissolved for chrysotile-gypsum and 0.63 to $5.39 \mathrm{mg} . \mathrm{L}^{-1}$ for amositegypsum. For chrysotile-gypsum, 25\% of the siderophores were in the PVD-Fe complex form, whereas PVD was almost saturated at 100\% for amosite-gypsum, a factor that may have limited material weathering. A higher amount of extracted iron was obtained for amosite-gypsum, which is consistent with the chemical composition of this material, which contains more iron than chrysotile-gypsum. Iron removal was not the same for all PVDs. Moreover, the PVD which extracted the most iron was different, depending on the type of waste: PVD from P. mandelii for chrysotile-gypsum, with $1.22 \mathrm{mg} . \mathrm{L}^{-1}$, and $P$. fluorescens for amosite-gypsum, with $5.39 \mathrm{mg} . \mathrm{L}^{-1}$. In addition, the amount of iron extracted from samples incubated in fresh supernatants for $48 \mathrm{~h}$ was the same as that measured after $24 \mathrm{~h}$ (data not shown). Studies examining siderophoremediated iron dissolution from chrysotile waste are lacking. A few studies have focused on the effect of the commercial bacterial siderophore desferrioxamine, produced by Streptomyces pilosus, on asbestos fibers. Iron removal from crocidolite and amosite by this siderophore is also effective (Chao and Aust, 1994). Moreover, Mohanty et al. (2018) showed that desferrioxamine releases exchangeable and structural iron from chrysotile fibers in a concentration-dependent manner. Other studies have shown that fungal strains can extract iron from asbestos, likely promoted by siderophores (Daghino et al., 2008). Mohanty et al. (2018) showed that desferrioxamine was as effective as the fungi siderophore, ferrichrome, in removing iron from chrysotile fibers.

\subsection{Kinetics of iron extraction from chrysotile-gypsum by pyoverdines}

We then focused on the most representative ACW among waste, chrysotile-gypsum. Based on the results show in Fig. 1, we carried out waste alteration using the two PVD-containing

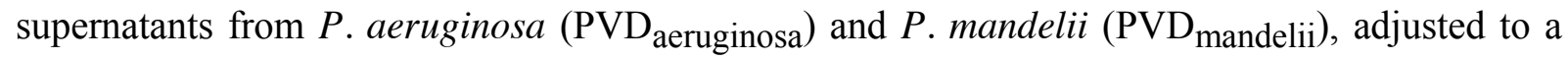
final concentration of $100 \mu \mathrm{M}$ (Fig. 2). We sampled and measured iron solubilization during the 
first $8 \mathrm{~h}$ and at the end of the incubation to better understand the iron extraction kinetics. The kinetic profiles of dissolution by the two PVDs were very similar and achieved the same iron extraction $\left(0.9 \mathrm{mg} . \mathrm{L}^{-1}\right)$ at the end of the experiment, consistent with the results presented in Fig. 1. We detected dissolved iron for $\mathrm{PVD}_{\text {mandelii }}$ and $\mathrm{PVD}_{\text {aeruginosa }}$ after only $1 \mathrm{~h}$ of contact $(0.12$ and $0.17 \mathrm{mg} . \mathrm{L}^{-1}$, respectively), which progressively increased during the next $8 \mathrm{~h}$ of dissolution (0.59 and $0.54 \mathrm{mg} . \mathrm{L}^{-1}$, respectively). The same time scale of $24 \mathrm{~h}$ was used by Mohanty et al. (2018) to reach an iron dissolution equilibrium for chrysotile fiber weathering by desferrioxamine. However, we cannot compare the iron concentrations because our experiment focused on chrysotile waste embedded in gypsum for flocking purposes in housing, whereas that of Mohanty et al. used raw asbestos fibers.

\subsection{Long-term alteration of chrysotile-gypsum by pyoverdines}

Our experiments clearly show that the optimum time for chrysotile-gypsum alteration is 24 $\mathrm{h}$ without renewal of the medium. We conducted a second set of experiments, with periodic medium renewal, for 42 days on FAW to determine the limit of iron extraction by PVDs produced by $P$. aeruginosa and P. mandelii. The supernatant was replaced by fresh apo-PVD supernatant at each cycle. $\mathrm{PVD}_{\text {aeruginosa }}$ and $\mathrm{PVD}_{\text {mandelii }}$ showed equivalent iron release over time, which is consistent with the previous results. Succinate medium alone had no effect on iron dissolution, as only low iron concentrations were detected in the control $\left(0.01\right.$ to $\left.0.08 \mathrm{mg} . \mathrm{L}^{-1}\right)$ (Fig. 3). During the $24 \mathrm{~h}$ cycles (T24-1 to T24-8), using siderophore concentrations of $100 \mu \mathrm{M}$, iron extraction decreased from 0.92 to $0.28 \mathrm{mg}^{-\mathrm{L}^{-1}}$ for $\mathrm{PVD}_{\text {aeruginosa }}$ and 0.88 to $0.22 \mathrm{mg} . \mathrm{L}^{-1}$ for $\mathrm{PVD}_{\text {mandelii }}$ We observed an unexpected increase to 0.42 for $\mathrm{PVD}_{\text {aeruginosa }}$ and 0.37 for PVD $_{\text {mandelii }}$ for T24-9, due to a longer stand-by period (a week) between T24-8 and T24-9 than for the other cycles, for which the duration was $<72 \mathrm{~h}$. Thus, the cycles were extended to $96 \mathrm{~h}$ for seven cycles. At T96-1, iron dissolution was $0.55 \mathrm{mg} . \mathrm{L}^{-1}$ for $\mathrm{PVD}_{\text {aeruginosa }}$ and $0.45 \mathrm{mg} . \mathrm{L}^{-1}$ for PVD mandelii. After T96-2, released iron decreased to $0.24 \mathrm{mg} . \mathrm{L}^{-1}$ for $\mathrm{PVD}_{\text {aeruginosa }}$ and 0.25 mg. $\mathrm{L}^{-1}$ for $\mathrm{PVD}_{\text {mandelii }}$ and remained constant between T96-5 and T96-7. Then, we incubated 
the chrysotile-gypsum in a $200 \mu \mathrm{M}$ PVD-containing supernatant for 24 and $96 \mathrm{~h}$ to determine whether additional iron could be extracted. However, the concentration of solubilized iron was very low (0.17 for $\mathrm{PVD}_{\text {aeruginosa }}$ and $0.09 \mathrm{mg} . \mathrm{L}^{-1}$ for $\mathrm{PVD}_{\text {mandelii }}$ after $96 \mathrm{~h}$ ). The waste contains chrysotile, with a theoretical composition of $\mathrm{Mg}_{3} \mathrm{Si}_{2} \mathrm{O}_{5}(\mathrm{OH})_{4}$, which is a sheet silicate composed of inner tetrahedral silicate layers and outer magnesium oxide octahedral layers (brucite). Since asbestos originated from soils where iron is highly abundant, magnesium in the outer layer may be replaced by ferrous and ferric iron. The same phenomenon may occur in the inner silicate layer, where silicon may be exchanged by ferric iron only (Pollastri et al., 2015). In our study, some iron appeared to be more easily solubilized during short-term assay $(24 \mathrm{~h})$, whereas we needed to increase the exposure time to $96 \mathrm{~h}$ to continue iron dissolution. It is well known that siderophore-mediated iron removal leads to siderophore adsorption on the ironbearing mineral surface. For example, PVD has already been shown to dissolve structural iron from smectite upon contact (Ferret et al., 2014). A few studies have focused on siderophore dissolution mechanism for mineral asbestos. Mohanty et al. (2018) studied iron release from chrysotile fibers, depending on the concentration of desferrioxamine in long-term experiments with no solution renewal. The low concentration of desferrioxamine $(1 \mu \mathrm{M})$ released some iron from the surface of the brucite layer, whereas increasing the concentration of desferrioxamine to $10 \mu \mathrm{M}$ led to better surface coverage. Exhaustion of surface sites could provide easier access to the iron present in the silica tetrahedron. In our experiment, the concentration of both siderophores remained predominantly constant $(100 \mu \mathrm{M})$ and the solutions were renewed at regular intervals of $24 \mathrm{~h}$ or $96 \mathrm{~h}$. Our results tend to point to the same conclusion as those of Mohanty et al. (2018), in which short renewal cycles appear to release iron from the brucite layer, leaching the fiber surface and potentially providing access to iron from the silica layer. The increase in iron removal by the $96 \mathrm{~h}$ renewal cycles could be explained by two mechanisms: i) better siderophore surface coverage and the ii) release of iron from the silica layer. As iron dissolution from the silica tetrahedron could be slow, our long renewal cycles may have facilitated such weathering.

Analysis of chrysotile fibers by STEM-EDX (Fig. 4) showed a large decrease of iron content after long-term alteration with both PVDs and confirms that iron was removed from the 
structure. Interestingly, the silica content tended also to decrease after PVD contact. These results confirm active dissolution driven by the siderophores.

\subsection{Effect of pyoverdine concentrations on iron and magnesium dissolution from chrysotile-gypsum}

Various concentrations of $\mathrm{PVD}_{\text {mandelii }}$ were added to FAW over $48 \mathrm{~h}$ to evaluate iron and magnesium release. We observed iron removal from chrysotile fibers in a dose-dependent manner (Fig. 5A). The control (succinate medium alone) showed only weak dissolution (0.034

mg. $\mathrm{L}^{-1}$ ), whereas iron release was significantly higher in the presence of PVD from $0.30 \mathrm{mg} . \mathrm{L}^{-1}$ at $25 \mu \mathrm{M}$ to $0.96 \mathrm{mg} . \mathrm{L}^{-1}$ at $150 \mu \mathrm{M}$. The amount of iron released by $200 \mu \mathrm{M}$ PVD was similar to that released by $150 \mu \mathrm{M}$, showing that the PVD concentration was not a limiting factor. Indeed, $10 \%$ of the siderophore was in a PVD-Fe complex form at $200 \mu \mathrm{M}$. Thus, the reaction involved a proportion of apo-PVD which could be high enough to extract iron, indicating that the limiting factor could be the availability of iron. Mohanty et al. (2018) showed that iron removal from chrysotile fibers increased if the concentration of desferrioxamine was raised from 1 to $10 \mu \mathrm{M}$. Our results confirm this study and suggest that iron release is limited by iron availability. Siderophores are well known for their high affinity for iron and recently Schalk et al. (2011) demonstrated that other metals can also be chelated by the PVD of P. aeruginosa. However, no data are available on the capacity of PVD to complex magnesium. Given that the studied FAW contains chrysotile with an external brucite layer composed of magnesium, fiber alteration may result in magnesium solubilization. We thus evaluated the effect of $\mathrm{PVD}_{\text {mandelii }}$ on magnesium dissolution as well as that of iron (Fig. 5B). We observed no effect on magnesium dissolution at any tested concentrations. A relatively high magnesium concentration was measured in the control (5.5 mg. $\left.\mathrm{L}^{-1}\right)$, with no significative difference from the amount of magnesium dissolved by $\mathrm{PVD}_{\text {mandelii }}\left(3.85 \mathrm{mg} . \mathrm{L}^{-1}\right.$ to $\left.6.89 \mathrm{mg} . \mathrm{L}^{-1}\right)$, regardless of the concentration tested. $\mathrm{pH}$ is a well-known parameter that has been described to influence the dissolution of the chrysotile brucite layer (Choi and Smith, 1972; Gronow, 1987). An acidic environment could strongly favor magnesium ion leaching, whereas slower dissolution kinetics may occur at neutral $\mathrm{pH}$. All 

been due to the $\mathrm{pH}$

\section{Conclusions}

\section{Acknowledgements} Company of Zeolites).

\section{References}

We investigated the efficiency of various PVDs to scavenge iron from FAW and the ability of the best identified PVDs to degrade asbestos waste. Our results showed a significant iron extraction from FAW by all tested PVDs but with differences in efficiency according to the pyoverdines and the type of waste. PVD from P. mandelii extracted the higher amount of iron from chrysotile-gypsum, while PVD from P. fluorescens was the most efficient for amositegypsum. The kinetic profiles of iron extraction from chrysotile-gypsum by these pyoverdines highlighted a time-dependent dissolution. A long-term alteration of chrysotile-gypsum by $\mathrm{PVD}_{\text {aeruginosa }}$ and $\mathrm{PVD}_{\text {mandelii }}$ revealed an extraction limit after renewal cycles for a total of 42 days leading to a large decrease of iron content from chrysotile fibers structure. Moreover, $\mathrm{PVD}_{\text {mandelii }}$ extracted iron from chrysotile-gypsum in concentration-dependent manner. Our research identified efficient pyoverdines in biodegradation of asbestos waste. The resulting PVDFe complex could be exploited as a valuable iron source. Further investigations might allow to consider the development of an eco-friendly asbestos treatment, using pyoverdines, in order to reduce asbestos-related environmental and health problems.

This work was supported by the French Environment and Energy Management Agency (ADEME), the French R\&D plan for asbestos removal (PRDA) and SOMEZ (Mediterranean

Albrecht-Gary, A.-M., Blanc, S., Rochel, N., Ocaktan, A.Z., Abdallah, M.A., 1994. Bacterial iron transport: Coordination properties of pyoverdin $\mathrm{PaA}$, a peptidic siderophore of Pseudomonas aeruginosa. Inorg. Chem. 33, 6391-6402. https://doi.org/10.1021/ic00104a059 
Aouad, G., Crovisier, J.-L., Damidot, D., Stille, P., Hutchens, E., Mutterer, J., Meyer, J.-M., Geoffroy, V.A., 2008. Interactions between municipal solid waste incinerator bottom ash and bacteria (Pseudomonas aeruginosa). Sci. Total Environ. 393, 385-393. https://doi.org/10.1016/j.scitotenv.2008.01.017

Balducci, G., Foresti, E., Lelli, M., Lesci, I.G., Marchetti, M., Pierini, F., Roveri, N., 2012. Process for treating an asbestos containing material. EP2428254A1.

Briskot, G., Taraz, K., Budzikiewicz, H., 1989. Bacterial constituents, XXXVII. pyoverdin-type siderophores from Pseudomonas aeruginosa. Liebigs Annalen der Chemie 1989, 375-384. https://doi.org/10.1002/jlac.198919890164

Budzikiewicz, H., Schröder, H., Taraz, K., 2014. Zur biogenese der Pseudomonas-siderophore: Der nachweis analoger strukturen eines pyoverdin-desferriferribactin-paares. Zeitschrift für Naturforschung C 47, 26-32. https://doi.org/10.1515/znc-1992-1-206

Chao, C.C., Aust, A.E., 1994. Effect of long-term removal of iron from asbestos by desferrioxamine B on subsequent mobilization by other chelators and induction of DNA singlestrand breaks. Arch. Biochem. Biophys. 308, 64-69. https://doi.org/10.1006/abbi.1994.1009

Choi, I., Smith, R.W., 1972. Kinetic study of dissolution of asbestos fibers in water. J. Colloid Interface Sci. 40, 253-262. https://doi.org/10.1016/0021-9797(72)90014-8

Dabboussi, F., Hamze, M., Singer, E., Geoffroy, V., Meyer, J.-M., Izard, D., 2002. Pseudomonas mosselii sp. nov., a novel species isolated from clinical specimens. Int. J. Syst. Evol. Microbiol. 52, 363-376. https://doi.org/10.1099/00207713-52-2-363

Daghino, S., Martino, E., Perotto, S., 2010. Fungal weathering and implications in the solubilization of metals from soil and from asbestos fiber. Current research, technology and education topics in applied microbiology and microbial biotechnology 1, 329-338.

Daghino, S., Martino, E., Vurro, E., Tomatis, M., Girlanda, M., Fubini, B., Perotto, S., 2008. Bioweathering of chrysotile by fungi isolated in ophiolitic sites. FEMS Microbiol Lett 285, 242 249. https://doi.org/10.1111/j.1574-6968.2008.01239.x

David, S.R., Ihiawakrim, D., Regis, R., Geoffroy, V.A., 2019. Iron removal from raw asbestos by siderophores-producing Pseudomonas. J. Hazard. Mater. 121563. https://doi.org/10.1016/j.jhazmat.2019.121563

Douguet, D., Carteron, H., Janiaud, P., Pinhas, N., 1997. Effets sur la santé des principaux types d'exposition à l'amiante. Institut national de la santé et de la recherche médicale (INSERM).

Favero-Longo, S.E., Castelli, D., Fubini, B., Piervittori, R., 2009. Lichens on asbestos-cement roofs: Bioweathering and biocovering effects. J. Hazard. Mater. 162, 1300-1308. https://doi.org/10.1016/j.jhazmat.2008.06.060

Favero-Longo, S.E., Turci, F., Tomatis, M., Castelli, D., Bonfante, P., Hochella, M.F., Piervittori, R., Fubini, B., 2005. Chrysotile asbestos is progressively converted into a non-fibrous amorphous material by the chelating action of lichen metabolites. J. Environ. Monit. 7, 764-766. https://doi.org/10.1039/B507569F 
Ferret, C., Sterckeman, T., Cornu, J.-Y., Gangloff, S., Schalk, I.J., Geoffroy, V.A., 2014. Siderophore- promoted dissolution of smectite by fluorescent Pseudomonas. Environ. Microbiol. Rep. 6, 459-467. https://doi.org/10.1111/1758-2229.12146

Gronow, J.R., 1987. The dissolution of asbestos fibres in water. Clay Minerals 22, 21-35. https://doi.org/10.1180/claymin.1987.022.1.03

Hohlneicher, U., Hartmann, R., Taraz, K., Budzikiewicz, H., 2014. Pyoverdin, ferribactin, azotobactin - a new triade of siderophores from Pseudomonas chlororaphis ATCC 9446 and its relation to Pseudomonas fluorescens ATCC 13525. Zeitschrift für Naturforschung C 50, 337344. https://doi.org/10.1515/znc-1995-5-602

Jülich, M., Taraz, K., Budzikiewicz, H., Geoffroy, V., Meyer, J.-M., Gardan, L., 2014. The structure of the pyoverdin isolated from various Pseudomonas syringae pathovars. Zeitschrift für Naturforschung C 56, 687-694. https://doi.org/10.1515/znc-2001-9-1003

Meyer, J.M., Abdallah, M.A., 1978. The fluorescent pigment of Pseudomonas fluorescens: Biosynthesis, purification and physicochemical properties. Microbiology 107, 319-328. https://doi.org/10.1099/00221287-107-2-319

Meyer, J.-M., Gruffaz, C., Raharinosy, V., Bezverbnaya, I., Schäfer, M., Budzikiewicz, H., 2008. Siderotyping of fluorescent Pseudomonas: Molecular mass determination by mass spectrometry as a powerful pyoverdine siderotyping method. Biometals 21, 259-271. https://doi.org/10.1007/s10534-007-9115-6

Meyer, J.-M., Stintzi, A., Coulanges, V., Shivaji, S., Voss, J.A., Taraz, K., Budzikiewic, H., 1998. Siderotyping of fluorescent pseudomonads: Characterization of pyoverdines of Pseudomonas fluorescens and Pseudomonas putida strains from Antarctica. Microbiology 144, 3119-3126. https://doi.org/10.1099/00221287-144-11-3119

Mohanty, S.K., Gonneau, C., Salamatipour, A., Pietrofesa, R.A., Casper, B., ChristofidouSolomidou, M., Willenbring, J.K., 2018. Siderophore-mediated iron removal from chrysotile: Implications for asbestos toxicity reduction and bioremediation. J. Hazard. Mater. 341, 290-296. https://doi.org/10.1016/j.jhazmat.2017.07.033

Paolini, V., Tomassetti, L., Segreto, M., Borin, D., Liotta, F., Torre, M., Petracchini, F., 2019. Asbestos treatment technologies. J. Mater. Cycles Waste Manag. 21, 205-226. https://doi.org/10.1007/s10163-018-0793-7

Persmark, M., Frejd, T., Mattiasson, B., 1990. Purification, characterization, and structure of pseudobactin 589 A, a siderophore from a plant growth promoting Pseudomonas. Biochemistry 29, 7348-7356. https://doi.org/10.1021/bi00483a026

Pollastri, S., D’Acapito, F., Trapananti, A., Colantoni, I., Andreozzi, G.B., Gualtieri, A.F., 2015. The chemical environment of iron in mineral fibres. A combined X-ray absorption and Mössbauer spectroscopic study. J. Hazard. Mater. 298, 282-293. https://doi.org/10.1016/j.jhazmat.2015.05.010

Rajkumar, M., Vara Prasad, M.N., Freitas, H., Ae, N., 2009. Biotechnological applications of 
serpentine soil bacteria for phytoremediation of trace metals. Crit. rev. biotechnol. 29, 120-130. https://doi.org/10.1080/07388550902913772

Schalk, I.J., Hannauer, M., Braud, A., 2011. New roles for bacterial siderophores in metal transport and tolerance. Environ. Microbiol. 13, 2844-2854. https://doi.org/10.1111/j.14622920.2011.02556.x

Scherpereel, A., 2016. Amiante et pathologie respiratoire. La Presse Médicale, Médecine et environnement 45, 117-132. https://doi.org/10.1016/j.lpm.2015.12.011

Spasiano, D., Luongo, V., Petrella, A., Alfè, M., Pirozzi, F., Fratino, U., Piccinni, A.F., 2017. Preliminary study on the adoption of dark fermentation as pretreatment for a sustainable hydrothermal denaturation of cement-asbestos composites. J. Clean. Prod. 166, 172-180. https://doi.org/10.1016/j.jclepro.2017.08.029

Spasiano, D., Pirozzi, F., 2017. Treatments of asbestos containing wastes. J. Environ. Manage. 204, Part 1, 82-91. https://doi.org/10.1016/j.jenvman.2017.08.038

Teintze, M., Hossain, M.B., Barnes, C.L., Leong, J., Van der Helm, D., 1981. Structure of ferric pseudobactin: A siderophore from a plant growth promoting Pseudomonas. Biochemistry 20, 6446-6457. https://doi.org/10.1021/bi00525a025

Toyokuni, S., 2009. Mechanisms of asbestos-induced carcinogenesis. Nagoya J. Med. Sci. 71, 110 .

Valko, M., Jomova, K., Rhodes, C.J., Kuča, K., Musílek, K., 2015. Redox- and non-redox-metalinduced formation of free radicals and their role in human disease. Arch. Toxicol. 90, 1-37. https://doi.org/10.1007/s00204-015-1579-5

Virta, R.L., 2002. Asbestos: Geology, mineralogy, mining, and uses. US Department of the Interior. US Geological Survey.

Wang, D., Cullimore, D.R., 2010. Bacteriological challenges to asbestos cement water distribution pipelines. J. Environ. Sci. 22, 1203-1208. https://doi.org/10.1016/S10010742(09)60239-4

Wang, D., Cullimore, R., Hu, Y., Chowdhury, R., 2011. Biodeterioration of asbestos cement (AC) pipe in drinking water distribution systems. Int. Biodeterior. Biodegrad. 65, 810-817. https://doi.org/10.1016/j.ibiod.2011.05.004

Wasserbauer, R., Zadák, Z., Novotný, J., 1988. Nitrifying bacteria on the asbestos-cement roofs of stable buildings. International Biodeterioration 24, 153-165. https://doi.org/10.1016/02653036(88)90045-0

Wong-Lun-Sang, S., Bernardini, J.-J., Hennard, C., Kyslík, P., Dell, A., Abdallah, M.A., 1996. Bacterial siderophores: Structure elucidation, 2D 1H and 13C NMR assignments of pyoverdins produced by Pseudomonas fluorescens CHAO. Tetrahedron Lett. 37, 3329-3332. https://doi.org/10.1016/0040-4039(96)00569-2 
FIGURE LEGENDS:

Fig. 1. Concentration of iron dissolved from flocking asbestos waste, chrysotile-gypsum (A) and amosite-gypsum (B), in the presence of various pyoverdine-containing supernatants (SN) after $24 \mathrm{~h}$ of contact. Error bars indicate the standard errors of the means of three or five replicates. Bars with the same letter are not significantly different $(p>0.05$, Kruskal-Wallis test, three or five replicates).

Fig. 2. Evolution of iron concentration extracted from chrysotile-gypsum waste over $24 \mathrm{~h}$ in the presence of Pseudomonas aeruginosa or Pseudomonas mandelii pyoverdine-containing supernatants (SN). Error bars indicate the standard errors of the means of five replicates.

Fig. 3. Iron removal from chrysotile-gypsum waste after renewal cycles of 24 or $96 \mathrm{~h}$ in the presence of $100 \mu \mathrm{M}$ (T24-1 to T24-9 and T96-1 to T96-7) or $200 \mu \mathrm{M}$ (T24-C and T96-C) Pseudomonas aeruginosa or Pseudomonas mandelii pyoverdine-containing supernatants (SN). Error bars indicate the standard errors of the means of five replicates.

Fig. 4. STEM images and STEM mapping of chrysotile-gypsum fibers after renewal cycles of 24 or $96 \mathrm{~h}$ in the presence of succinate medium (a and b) or Pseudomonas mandelii pyoverdinecontaining supernatants (SN) (c and d). Large images obtained from the combination of the three distributions of $\mathrm{Mg}, \mathrm{Si}$, and $\mathrm{Fe}$ with analysis areas (a and c). Atomic ratios of $\mathrm{Mg} / \mathrm{Si}$ and $\mathrm{Fe} / \mathrm{Si}$ (b and d). (e) Comparison histogram after renewal cycles with succinate medium or Pseudomonas mandelii pyoverdine-containing supernatants.

Fig. 5. Effect of various concentrations of pyoverdine produced by Pseudomonas mandelii on iron (A) and magnesium (B) dissolution from chrysotile-gypsum waste after $48 \mathrm{~h}$ of contact. Error bars indicate the standard errors of the means of five replicates. Bars with the same letter are not significantly different ( $p>0.05$, Kruskal-Wallis test of five replicates). 
Highlights

- Weathering efficiency varies according to the pyoverdines and the type of waste.

- Pyoverdines solubilize iron in a time-dependent manner.

- Chrysotile-gypsum weathering by pyoverdines decreases iron concentration in fibers.

- Iron removal from chrysotile-gypsum is concentration-dependent of pyoverdines.

- Pyoverdines could be used in bioremediation process of asbestos waste. 
1 Table 1. List of pyoverdines used, with their molecular mass, isoelectrofocusing 2 characteristics, and peptide composition.

\begin{tabular}{|c|c|c|c|c|c|c|}
\hline Siderovars & Species & MM & & $\begin{array}{l}\text { nber of } \\
\text { orms and } \\
\text { values }\end{array}$ & Pyoverdine peptide chain & References \\
\hline Lille 1 & P. monteilii & 1291 & 2 & $7.3 / 4.6$ & Asp-Lys-AcOHOrn-Ala-Ser-Ser-Gly-Ser-cOHOrn & $\begin{array}{l}\text { Meyer et al. } \\
(2008)\end{array}$ \\
\hline Syr & P. syringae & 1123 & 2 & $5.0 / 4.0$ & $\varepsilon$ Lys-OHAsp-Thr-(Thr-Ser-OHAsp-Ser) & $\begin{array}{l}\text { Jülich et al. } \\
\text { (2014) }\end{array}$ \\
\hline $\begin{array}{l}\text { B10/PL9/ } \\
\text { 7SR1/A225 }\end{array}$ & P. lini & 989 & 3 & 7.5/5.2/4.6 & $\varepsilon$ Lys-OHAsp-Ala-aThr-Ala-cOH $\underline{\text { Orn }}$ & $\begin{array}{l}\text { Teintze et al. } \\
\text { (1981) }\end{array}$ \\
\hline 12633 & P.putida & 1336 & 3 & 4.6/4.2/4.0 & 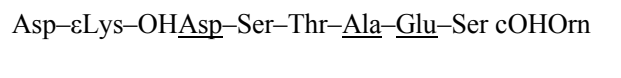 & $\begin{array}{l}\text { Persmark et al. } \\
\text { (1990) }\end{array}$ \\
\hline Lille 17 & P.mosselii & - & 3 & $9.0 / 7.4 / 5.2$ & ND & $\begin{array}{l}\text { Dabboussi et } \\
\text { al. (2002) }\end{array}$ \\
\hline 13525 & P.fluorescens & 1160 & 3 & $8.7 / 7.3 / 7.1$ & $\underline{\text { Ser-Lys-Gly-FOHOrn-(Lys-FOHOrn-Ser) }}$ & $\begin{array}{l}\text { Hohlneicher et } \\
\text { al. (2014) }\end{array}$ \\
\hline CHA0 & P.fluorescens & 1287 & 3 & $8.5 / 7.5 / 5.1$ & Asp-FOHOrn-Lys-(Thr- $\underline{\text { Ala }} \underline{-}-\underline{\text { Ala }} \underline{\text {-FOHOrn-Lys) }}$ & $\begin{array}{l}\text { Wong-Lun- } \\
\text { Sang et al. } \\
\text { (1996) }\end{array}$ \\
\hline PAO1 & P.aeruginosa & 1333 & 2 & $8.8 / 7.0$ & $\underline{\text { Ser-Arg-Ser-FOHOrn-(Lys-FOHOrn-Thr-Thr) }}$ & $\begin{array}{l}\text { Briskot et al. } \\
\text { (1989) }\end{array}$ \\
\hline SB8.3 & P. mandelii & 1046 & 3 & $9.0 / 8.8 / 7.6$ & $\underline{\text { Ala-Lys-Thr-Ser-AOHOrn-cOHOrn }}$ & $\begin{array}{l}\text { Budzikiewicz } \\
\text { et al. (2014) }\end{array}$ \\
\hline
\end{tabular}

3 عLys: lys linked by its $\varepsilon$-NH2; OHAsp: threo- $\beta$-hydroxy-aspartic acid; aThr: allo-Thr; 4 cOHOrn: cyclo-hydroxy-ornithine; FOHOrn: $\delta \mathrm{N}$-formyl- $\delta \mathrm{N}$-hydroxy-ornithine; AOHOrn $5 \quad \delta \mathrm{N}$-acetyl- $\delta \mathrm{N}$-hydroxy-ornithine.

6 Parentheses indicate cyclic structures. D-amino acids are underlined. A broken line means 7 that the two enantiomers were detected among the underlined residues. ND: not determined. 


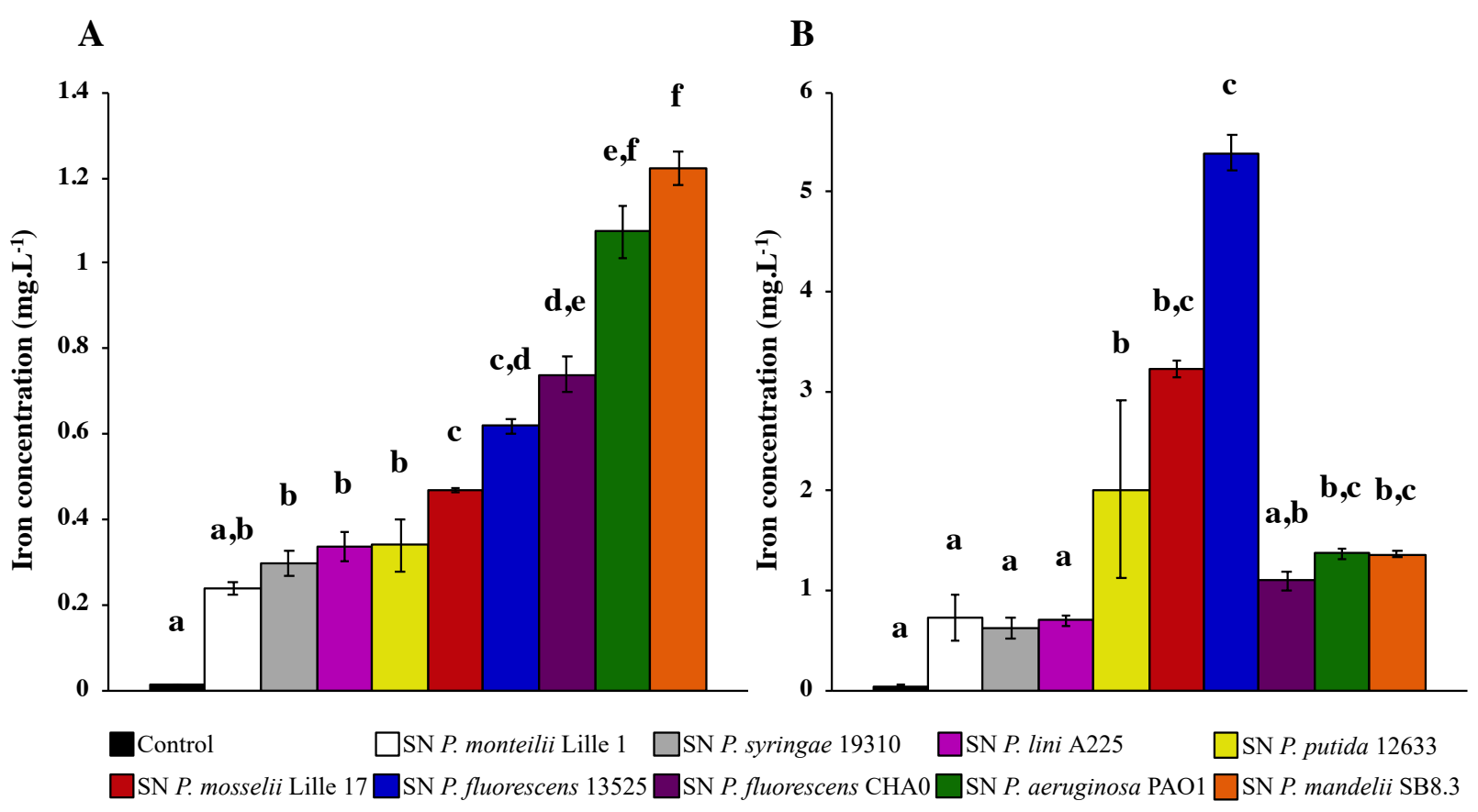

3 Fig. 1. Concentration of iron dissolved from flocking asbestos waste, chrysotile-gypsum (A) 4 and amosite-gypsum (B), in the presence of various pyoverdine-containing supernatants (SN) 5 after $24 \mathrm{~h}$ of contact. Error bars indicate the standard errors of the means of three or five 6 replicates. Bars with the same letter are not significantly different $(p>0.05$, Kruskal-Wallis 7 test, three or five replicates).

8

\section{In color online}




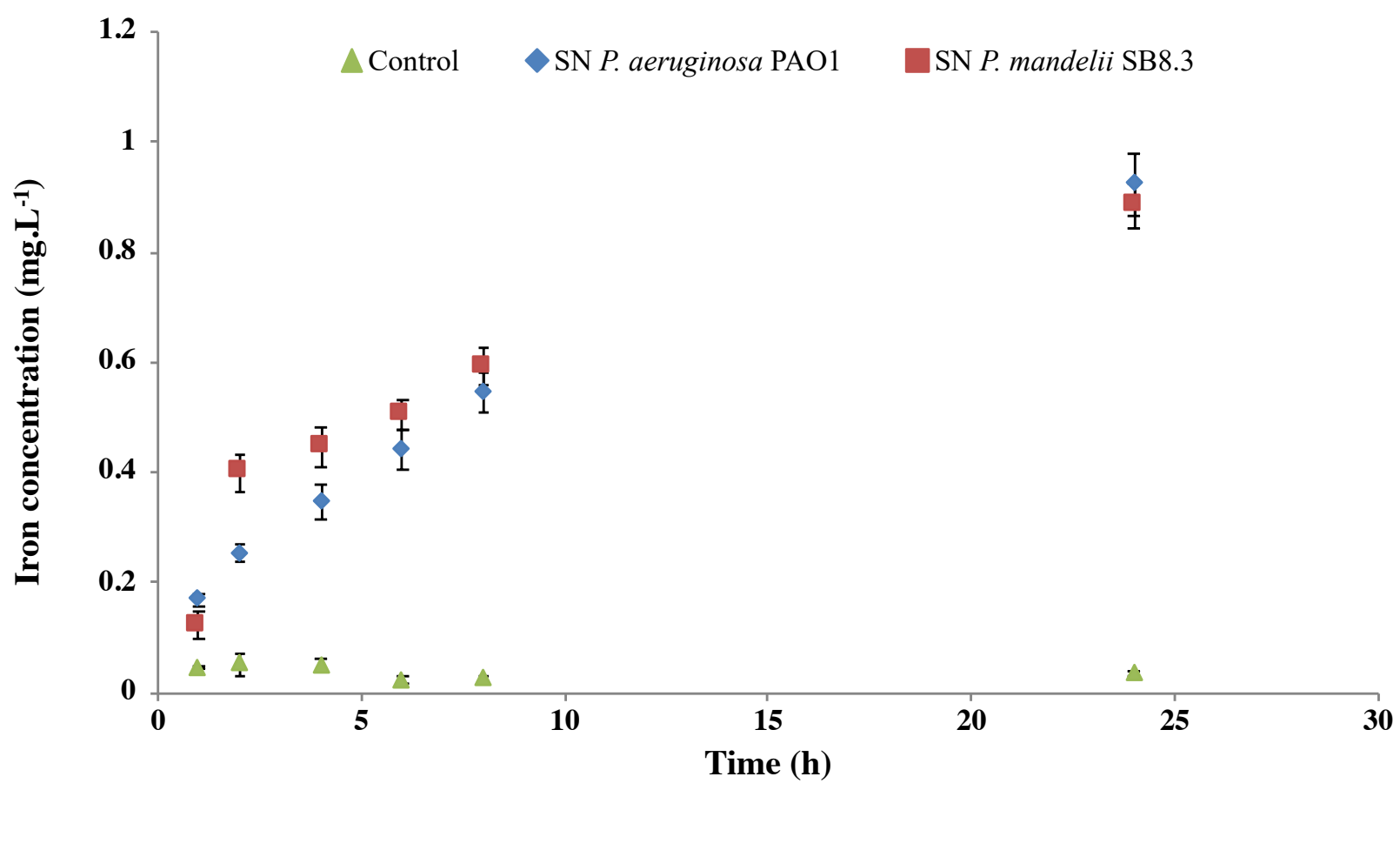

3 Fig. 2. Evolution of iron concentration extracted from chrysotile-gypsum waste over $24 \mathrm{~h}$ in 4 the presence of Pseudomonas aeruginosa or Pseudomonas mandelii pyoverdine-containing 5 supernatants ( $\mathrm{SN}$ ). Error bars indicate the standard errors of the means of five replicates.

6

7 In color online

8 


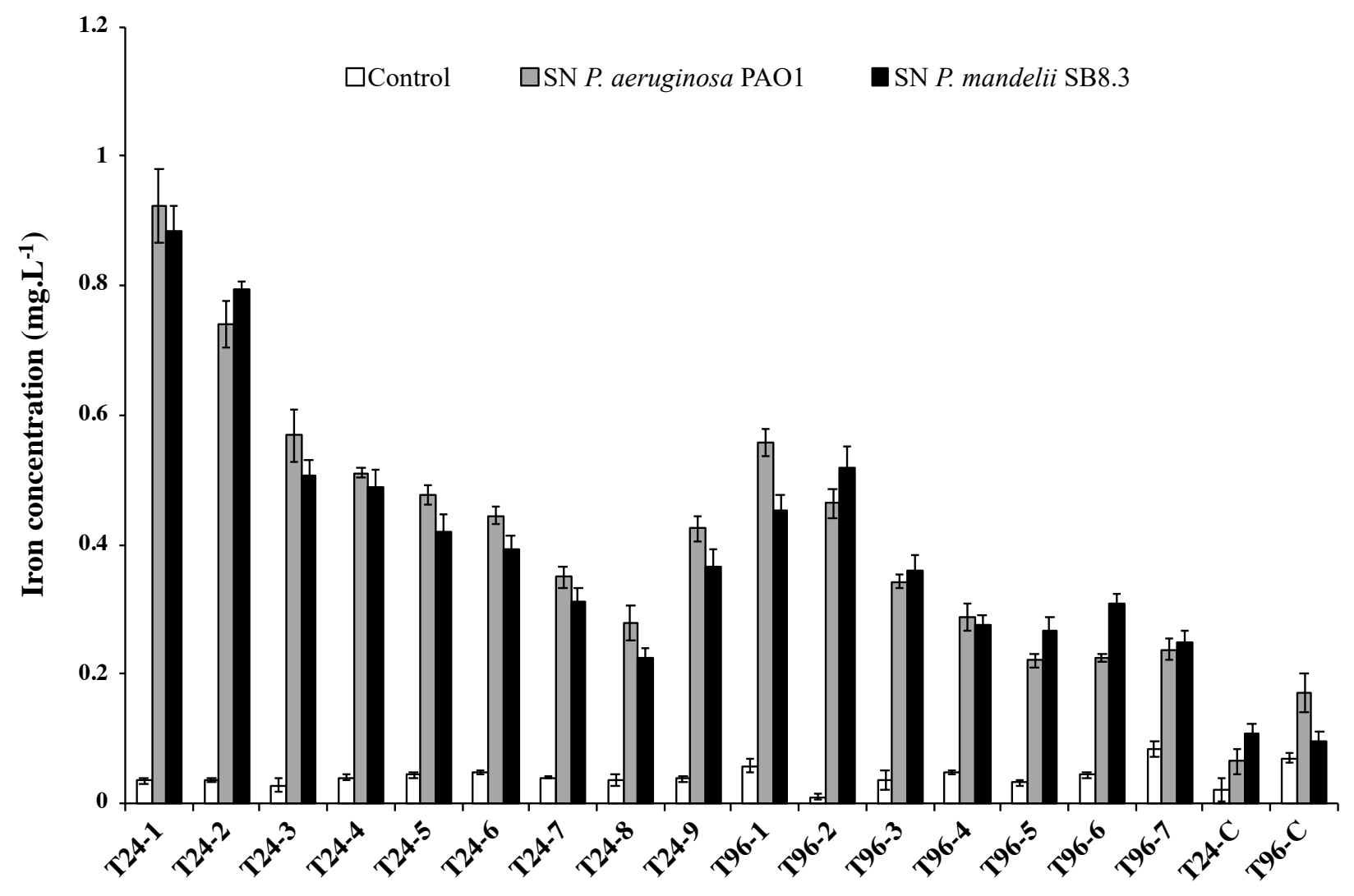

2

3 Fig. 3. Iron removal from chrysotile-gypsum waste after renewal cycles of 24 or $96 \mathrm{~h}$ in the 4 presence of $100 \mu \mathrm{M}$ (T24-1 to T24-9 and T96-1 to T96-7) or $200 \mu \mathrm{M}$ (T24-C and T96-C) 5 Pseudomonas aeruginosa or Pseudomonas mandelii pyoverdine-containing supernatants 6 (SN). Error bars indicate the standard errors of the means of five replicates. 
a

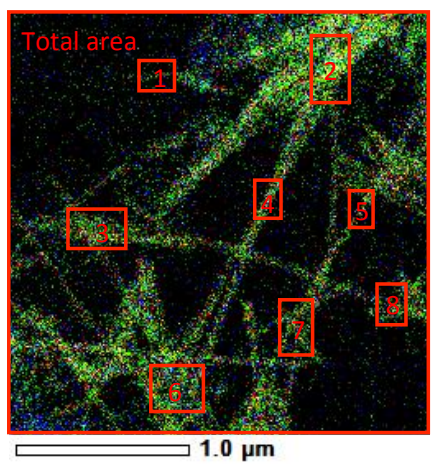

b

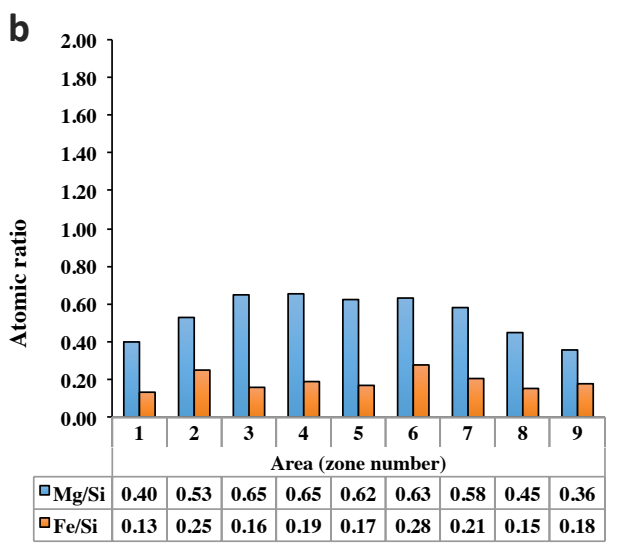

C

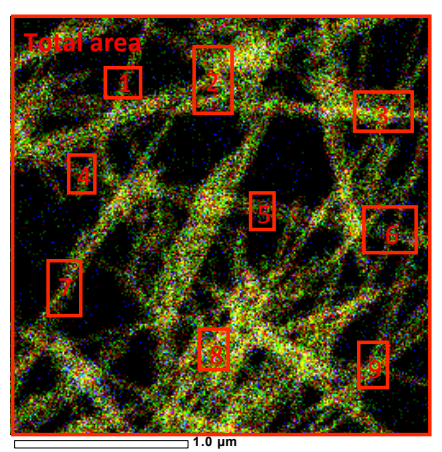

d

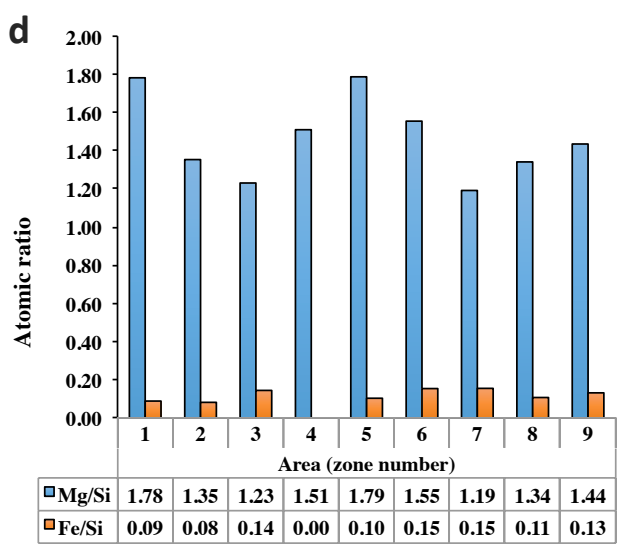

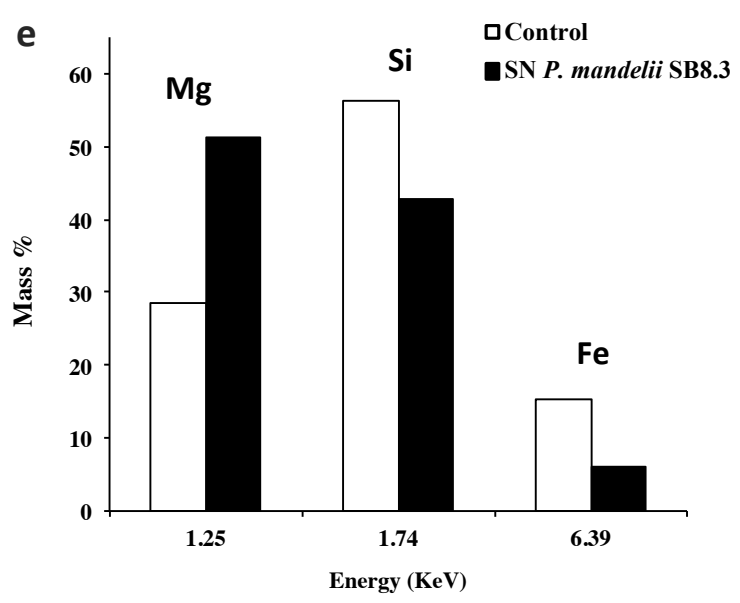

3 Fig. 4. STEM images and STEM mapping of chrysotile-gypsum fibers after renewal cycles of 424 or $96 \mathrm{~h}$ in the presence of succinate medium ( $\mathrm{a}$ and b) or Pseudomonas mandelii 5 pyoverdine-containing supernatants $(\mathrm{SN})$ ( $\mathrm{c}$ and $\mathrm{d}$ ). Large images obtained from the 6 combination of the three distributions of $\mathrm{Mg}, \mathrm{Si}$, and $\mathrm{Fe}$ with analysis areas (a and c). Atomic 7 ratios of $\mathrm{Mg} / \mathrm{Si}$ and $\mathrm{Fe} / \mathrm{Si}$ (b and d). (e) Comparison histogram after renewal cycles with 8 succinate medium or Pseudomonas mandelii pyoverdine-containing supernatants. 
A

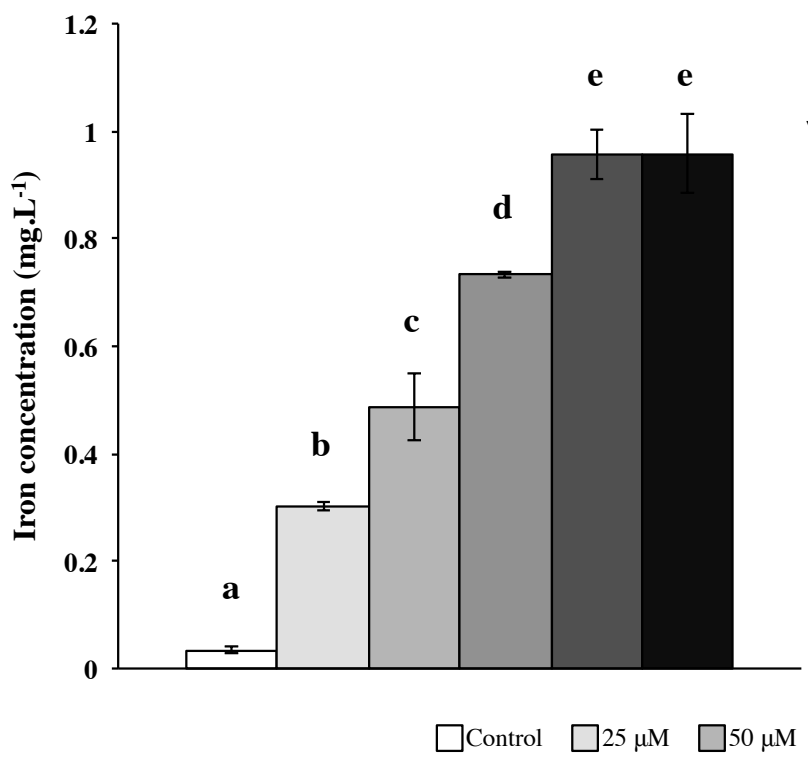

B

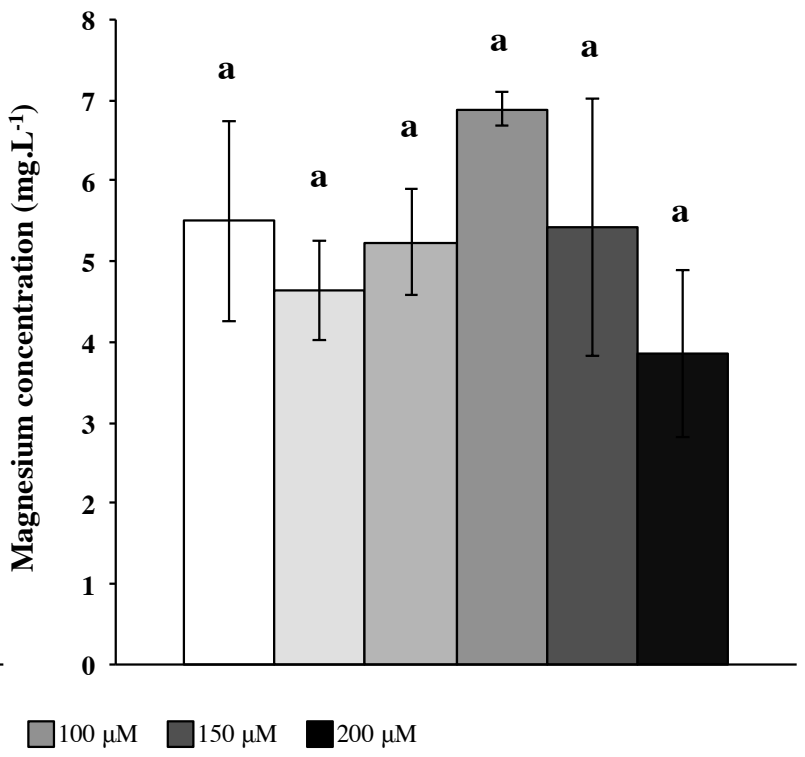

2

3 Fig. 5. Effect of various concentrations of pyoverdine produced by Pseudomonas mandelii on 4 iron (A) and magnesium (B) dissolution from chrysotile-gypsum waste after $48 \mathrm{~h}$ of contact. 5 Error bars indicate the standard errors of the means of five replicates. Bars with the same 6 letter are not significantly different ( $p>0.05$, Kruskal-Wallis test of five replicates). 
Graphical Abstract

2

3
4

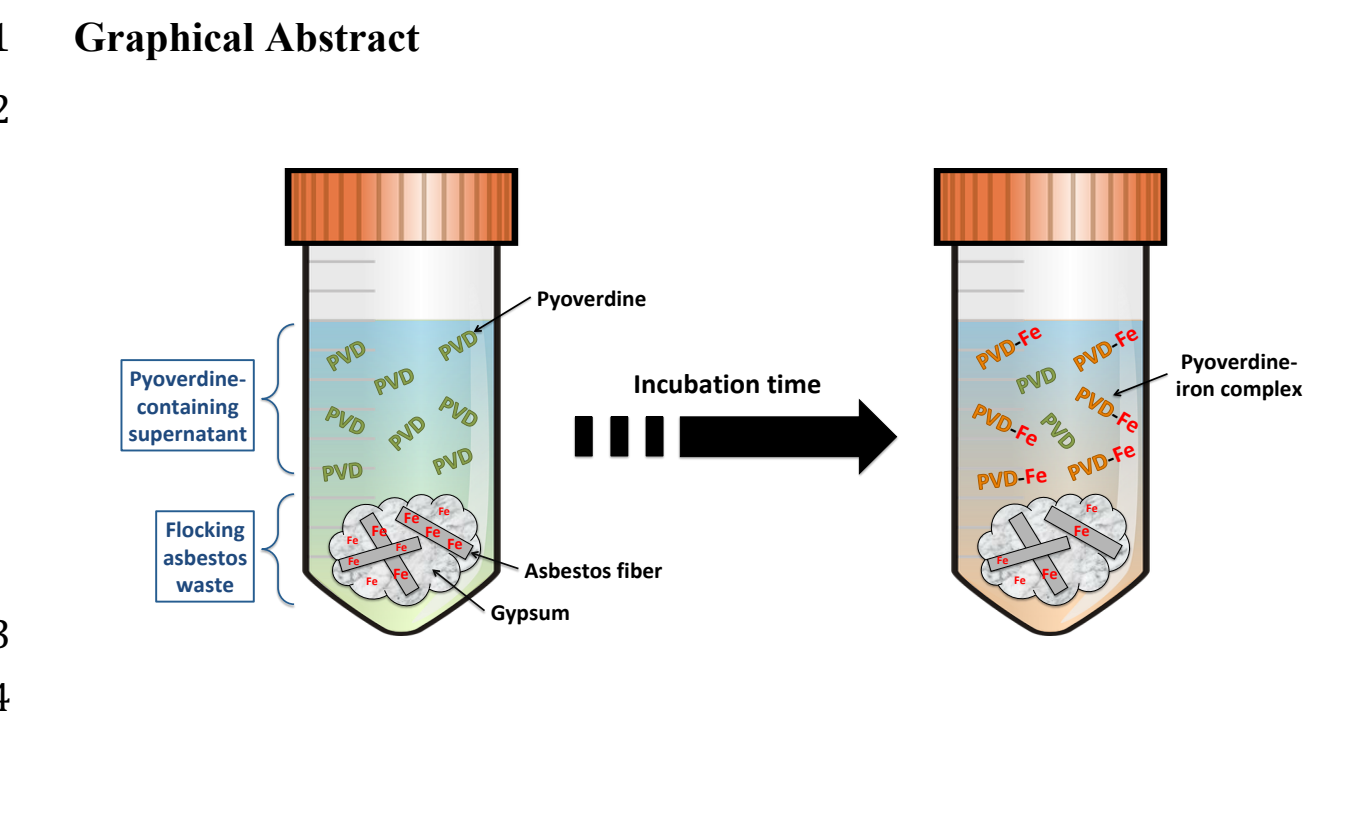

3
4

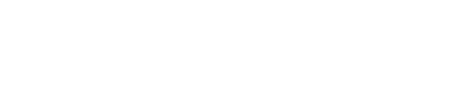

\section{Graphical Abstract}

2

\section{Graphical Abstract}

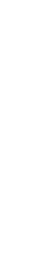

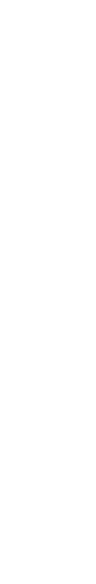

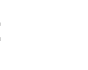

